\title{
¿PARA QUÉ NOS SIRVEN LOS EXTRANJEROS?*
}

\author{
JORGE LARROSA *
}

\begin{abstract}
Mantener despierto el dolor y provocar el deseo (...), esa es la tarea del verdadero educador en nuestro tiempo.

(M. BUBER)

El extranjero te permite ser tú mismo haciendo, de tí, un extranjer.
\end{abstract}

RESUMEN: En ese texto, propongo que la retórica multicultural que hoy prolifera en el campo pedagógico puede ser tratada en términos de la imagen que produce de nosotros mismos o, dicho de otro modo, en en la construcción de nuestra propia identidad. Esa retórica funciona también como un mecanismo para conjurar lo que el otro extranjero pueda tener de inquietante para nosostros. Sospecho que palabras como "convivencia", "diálogo" o "pluralismo" estén siendo utilizadas de forma tan acrítica como la antigua "misión civilizadora" y estén alimentando también nuestra buena conciencia y una imagen confortable y satisfecha de nosotros mismos. Pero, el otro extranjero no se deja representar. No permite que nadie le represente y no quiere representar a nadie ni a nada. Cuales son las implicaciones de esa situación con la Educación?

Palabras-clave: Comprensión/autocomprensión. Extranjero. Extraño. Multiculturalismo. Novela de Formación (Bildungsroman).

\section{WHAT IS THE USE OF STRANGERS?}

ABSTRACT: I propose that the multicultural rhetoric, nowadays waxing in the field of pedagogy, can be treated in terms of the image of

\footnotetext{
* A Alex Masllorens.

** Professor titular da Universidade de Barcelona. E-mail: jlarrosa@d5.ub.es
} 
ourselves it produces, that is, through the construction of our own identity. Such rhetoric also works as a device to ward off whatever may worry us in the other, in the stranger. I suspect that such words as coexistence, dialog or pluralism are used with the same lack of criticism as civilizing mission used to be. They would thus feed our good consciousness and provide us a comfortable and satisfying image of ourselves. Yet, the others, strangers do not let themselves be represented. They do not allow anybody to represent them nor do they want to represent anything or anyone. What does all this imply for pedagogy?

Key words: Understanding/self-understanding. Stranger. Strange. Multiculturalism. Novel of Formation (Bildungsroman).

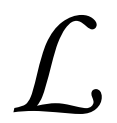

a comprensión, se nos dice, tendría una estructura reflexiva, sería algo así como un movimiento de ida (hacia el otro) y de vuelta (hacia uno mismo). Toda comprensión es retorno, dice Gadamer siguiendo a Hegel: "Reconocer en lo extraño lo propio, y hacerlo familiar, ese es el movimiento fundamental del espíritu, cuyo ser no es sino el retorno a sí mismo desde el ser del otro". Y Ricoeur, como en un eco: "Es el crecimiento de la propia comprensión de sí mismo (del intérprete) lo que éste persigue a través de su comprensión del otro. Toda hermenéutica es entonces, implícita o explícitamente, autocomprensión por medio de la comprensión de otros".

En la comprensión, el movimiento hacia el otro sería un momento mediador de la relación del intérprete consigo mismo. El otro no sería sino un rodeo, quizá necesario, en la permanente construcción y reconstrucción de lo mismo, la diferencia no sería sino un medio para el fortalecimiento de la identidad, la negatividad no sería sino un momento en el proceso de constitución de un sentido positivo, la comprensión del otro no sería sino una parte del trabajo requerido para el crecimiento de la autocomprensión. La estructura de la comprensión configuraría así al otro como un elemento en el juego de lo mismo, un juego en el que su identidad estática quedaría provisionalmente afectada por una cierta negatividad más o menos trucada de modo que el otro quedaría determinado como el lugar de una cierta resistencia en el que el intérprete se afectaría a sí mismo, se alteraría hacia sí mismo. Esquemáticamente: Mismo (Otro) $=$ Mismo.

Desde este punto de vista, quizá la locura no sea sino lo otro en relación a lo que la razón construye la imagen que tiene de sí misma, quizá la infancia no sea sino lo otro en relación a lo que la madurez construye la imagen que tiene de sí misma, y quizá los extranjeros no 
sean sino los (culturalmente) otros en relación a los que nosotros estamos empezando a fabricar una imagen de nosotros mismos, de nuestra cultura $y$ de nuestra casa en la que podamos reconocernos de una forma relativamente confortable.

Desde ahí, desde esa reflexividad implícita a la comprensión, quizá podamos tratar de ver el funcionamiento del discurso pedagógico sobre lo multicultural desde una perspectiva un tanto extraña: no tanto en relación a lo que ese discurso "dice" de los extranjeros sino, más bien, en relación a lo que ese discurso "hace" con nosotros mismos en tanto que nos identificamos con ese discurso. Mi hipótesis en lo que sigue es que la retórica multicultural que comienza a proliferar en el campo pedagógico puede ser tratada en términos de la imagen que produce de nosotros mismos o, dicho de otro modo, en tanto que dicha retórica trabaja en la construcción de nuestra propia identidad.

Por otra parte, esa retórica funciona también como un mecanismo para conjurar lo que el otro extranjero pueda tener de inquietante. Los discursos médico-psiquiátricos están ahí, entre otras cosas, para que la locura no inquiete a la razón, para darnos la seguridad de que nosotros no estamos locos, para que la locura sea siempre la de los otros, la que ya ha sido capturada por nuestros saberes y nuestras prácticas, la que ya no tiene nada que decir-nos. Los discursos psicopedagógicos están ahí para que la infancia no inquiete a la madurez, para que tengamos la certeza de que nosotros ya no somos niños, para que la infancia no ponga en cuestión lo que somos. Desde ese punto de vista, quizá entonces los discursos multiculturales estén ahí para dar un sentido confortable a nuestra relación con los extranjeros, para que lo extraño no inquiete lo propio, para que no nos extrañemos de nosotros mismos y para que, en el encuentro con el extranjero, no aprendamos que, en realidad, nosotros también somos extranjeros.

Podríamos decir que la comprensión procura un beneficio simbólico cuando su dimensión reflexiva se resuelve en un fortalecimiento de las seguridades que constituyen la identidad del intérprete. En ese sentido el otro extranjero es el que te permite sentirte en casa, el que te permite ser tú mismo haciendo de tí el (más o menos generoso) propietario de la casa. Podríamos localizar aquí la soberbia del sujeto de la comprensión, un sujeto que se reconoce en el optimismo de una racionalidad que no reconoce límites a la inteligibilidad de la existencia y en el poder de unas prácticas que no reconocen límites a la producción y la transformación del mundo social. El sujeto de la comprensión sería así el que hace de la comprensión un dispositivo de apropiación del 
mundo. Y quizá la arrogancia de esta imagen optimista, autosatisfecha y progresiva de nosotros mismos sea uno de los lugares en los que podría localizarse el "fundamentalismo" subyacente a casi todos los discursos sobre la educación multicultural.

La pregunta es, naturalmente, si es posible pensar una relación con el otro extranjero que permita mantener su potencialidad reflexiva, pero sin reducir lo que esa reflexividad pudiera tener de inquietante para la arrogancia de nuestros discursos, para la seguridad de nuestras prácticas y para la solidez de nuestra propia identidad. En ese caso el enunciado hermenéutico rezaría así: sentir la extrañeza de lo propio y no poder sentirse más en casa, ese es el movimiento fundamental del espíritu, cuyo ser no es sino la salida de sí mismo (su permanente puesta en cuestión) en el encuentro con el otro; es el derrumbe de la autocomprensión y la quiebra de la identidad lo que se produce en el encuentro con el otro; toda hermenéutica es entonces cuestionamiento de uno mismo, fractura de la autocomprensión, pérdida de la certeza de sí.

Junto a nosotros, los otros, los extranjeros, esos seres generalmente oscuros y siempre enigmáticos que ya no podemos ignorar tan fácilmente y cuya sola presencia provoca reacciones contradictorias, inquietantes a veces. Para dar sentido a nuestra relación con ellos (y para dar-nos un sentido en esa relación) hemos inventado eso de la "sociedad multicultural": una expresión ya trivializada y de uso común aunque no se sabe muy bien qué significa ni qué enmascara. A la vez descriptiva y prescriptiva, funciona como una representación de lo que ya sería nuestro mundo y como un emblema de los valores que deberían orientar una convivencia futura, quizá difícil, se nos dice, pero sin duda enriquecedora. Parece que ya vivimos en una sociedad multicultural (atravesada, por tanto, por ciertos conflictos históricamente inéditos en nuestro mundo) y parece también que deberíamos tratar de construir una "auténtica" sociedad multicultural, articulada por ciertos valores de tolerancia, de convivencia y de comunicación, en la que esos conflictos deberían ser racional, dialógica y democráticamente mediados para resolverse, al cabo, de una forma satisfactoria para todos. Los aparatos socio-policiales, asistenciales y pedagógico-culturales tratan de poner en marcha políticas que reduzcan los posibles riesgos y que potencien las virtualidades "positivas" de una sociedad así caracterizada. Y todos, o casi todos, nos sentimos un poco mejores en esa representación 
de nosotros mismos en la que aparecemos como miembros de una comunidad racional, democrática y acogedora que se esfuerza por ser abierta, tolerante, dialogante, respetuosa, comprensiva e integradora con esos seres extraños y venidos de afuera.

El campo intelectual de la educación (el que está compuesto por los "intelectuales de la educación": los especialistas, los profesores de universidad, los que escriben libros, dictan conferencias e imparten cursos, los "ideólogos" de lo educativo, los que diseñan políticas, los que hablan en los congresos, los "formadores de formadores", los que trabajan en los despachos, los que salen en la televisión, en los periódicos y en las revistas, los que tienen autoridad para hablar legítimamente, los que hacen "carrera" administrando el trabajo de los otros y conformando el sentido de sus prácticas) tan interesadamente abierto a plantearse los "retos del futuro", tan apresuradamente dispuesto siempre a "dar respuesta" a las "inquietudes del momento", sobre todo cuando son inquietudes morales, está comenzando a producir cantidades ingentes de bibliografía sobre el tema multicultural. Un poco por mimetismo de la bibliografía foránea (que siempre da una cierta legitimidad intelectual), un poco como resultado de una preocupación social más o menos fabricada por los medios de comunicación (de la que se obtiene una cierta legitimidad social), y un poco porque nuestras escuelas empiezan a tener extranjeros inmigrantes entre sus alumnos, los pedagogos han empezado a hablar de multiculturalismo en lugares como la televisión, las revistas, los libros, los salones de congresos, las salas de conferencias y las aulas universitarias.

Pero una pregunta, quizá un tanto perversa, se impone inmediatamente: ¿por qué será que los discursos que produce el "tema multicultural” contienen tanta autocomplacencia? ¿por qué eso del "multiculturalismo" se ha convertido tan rápidamente en una de esas "causas nobles" que atraviesan (y legitiman) el campo pedagógico dándonos como una íntima certidumbre de que trabajamos para la buena causa moral, para la causa de la humanidad? ¿por qué nos sentimos tan satisfechos de nosotros mismos cuando hacemos profesión de fe y de compromiso multicultural? ¿qué tipo de beneficio (simbólico) obtenemos con todo ello?

Hubo un tiempo no muy lejano en que era fácil exportar la cultura occidental con la convicción de que así llevábamos la verdad, la cultura y la felicidad a los pueblos miserables. La educación aparecía como una "misión civilizadora" y la "causa noble" a la que los pedagogos dedicaban sus mejores esfuerzos no era otra que la de ofrecer a las gentes de civilización 
"inferior" los "dones" de nuestra ciencia, nuestra cultura y nuestra forma de vivir. Ahora sabemos que la educación orientada a la "emancipación de los pueblos" ocultaba prácticas de normalización tecnocrática o moral de los comportamientos, cuando no justificaba la explotación pura y dura de las personas y los países. Pero, mientras tanto, los ciudadanos de las naciones de occidente se sentían bastante satisfechos de la evidente "superioridad" de sus formas de pensamiento y de sus normas de vida, al tiempo que alimentaban su soberbia moral con la gran tarea "civilizadora" que estaban realizando.

Hoy en día nuestros lemas se construyen con palabras como convivencia, diálogo o pluralismo y, sin duda, hemos ganado con el cambio. Pero debemos continuar sospechando que quizá esas palabras estén siendo utilizadas de forma tan acrítica como la antigua misión civilizadora y que acaso estén alimentando también nuestra buena conciencia, la íntima certidumbre de nuestra superioridad moral, y una imagen confortable y satisfecha de nosotros mismos.

El campo pedagógico no está ya investido del papel heroico que tuvo en otros tiempos (eso de la civilización contra la barbarie, el saber contra la ignorancia, la luz contra la oscuridad, las buenas costumbres contra la degradación moral y la promiscuidad, la ciencia contra la superstición, la humanidad contra el salvajismo, la razón contra la violencia), pero continúa necesitando de una cierta legitimidad social. Y el logro de esa legitimidad, más allá de los tópicos tecnocráticos y economicistas sobre el desarrollo y el progreso material, sigue jugándose en un terreno fundamentalmente moral. Y hoy que eso del multiculturalismo forma parte de la buena conciencia televisivamente mediatizada, aportar el granito de arena no deja de ser una buena inversión en el mercado simbólico de lo humanitario, ya bastante boyante y de asegurada rentabilidad. Así que los pedagogos, con su habitual generosidad un tanto interesada y con su particular sensibilidad para identificar los "retos del presente" y para presentar su trabajo como un medio privilegiado para "construir el futuro", han comenzando a hablar de multiculturalismo, y han comenzado a hacerlo tal como ellos generalmente hablan: diagnosticando la situación social, analizando los posibles problemas que se derivan, y proponiendo enseguida objetivos pedagógicos, estrategias educativas de actuación, materiales curriculares diversos y procedimientos para la evaluación de los resultados. Y jugando también a utilizar a su favor la carga emotiva que el tema lleva consigo. En el tema multicultural el discurso pedagógico continua saturado de efectos retóricos que van rápidamente de lo patético a lo profético, de la descripción emotivamente cargada de los problemas a la inmediata 
construcción de la escuela como el lugar en el que nos estamos jugando el futuro y, por tanto, en el que debemos aplicar nuestras mejores políticas para construir ese futuro de forma que sea habitable. El discurso pedagógico sobre lo multicultural conecta así perfectamente con ese sentido común trivialmente optimista, progresista y autosatisfecho que constituye hoy la imagen en la que el sujeto moderno se esfuerza en fabricarse para sí mismo

Y ahí, en la bibliografía pedagógica, una de las palabras mágicas es “comprensión". Los niños de la clase son (o van a ser), se dice, culturalmente diversos, heterogéneos. La tarea pedagógica, entonces, estaría encaminada a reducir los problemas que esa diversidad pueda traer consigo y a utilizar sus virtualidades positivas. Frente al doble peligro de los que preconizan la integración monocultural en nombre de la conformidad a un modelo de identidad único y de los que proclaman el "derecho a la diferencia" como una manera de segregar a los niños y de exacerbar los particularismos, la escuela multicultural se convertiría en el lugar del pluralismo, en el lugar, por tanto, de todos los riesgos y de todas las posibilidades. Pero sólo si el currículum es lo suficientemente diverso (desde el punto de vista cultural) y sólo si el espacio pedagógico se convierte en un lugar de verdadero diálogo (entre personas de diversas culturas de procedencia), sólo entonces sería posible que la escolarización permitiera que los niños (y los hombres del futuro) se reconocieran juntos en su humanidad (en su identidad genérica) y que compartieran esa humanidad en una forma de convivencia que no exigiera renegar de sus diferencias (de sus identidades particulares). Las diferencias deberían ser el lugar para la comprensión, es decir, para el ejercicio de un tipo de diálogo y de relación con el (culturalmente) otro que aseguraría la emergencia de una comunidad más plural a la que pertenecerían personas con una identidad cultural más compleja, con una mente más amplia, con unas formas de vida más flexibles y ricas, con un pensamiento más abierto y con un tono emocional más receptivo y tolerante.

Todos iguales, todos diferentes. He ahí el lema de la utopía multicultural que la escuela debería reproducir entre sus paredes y contribuir a producir fuera de ellas. Nada más y nada menos, se dice, que la producción de una nueva identidad y la construcción de un nuevo vínculo social en el que la diversidad cultural constituya el tejido de una sustancia ética nueva.

No sería difícil ironizar sobre lo fácilmente que la escuela convierte la "diferencia" en una serie de "cualidades diferenciales" sobre las que el saber y el poder hacen inmediatamente presa. La "atención a las diferencias", habitualmente considerada como una de las virtudes 
cardinales en materia educativa, deviene enseguida un mecanismo de adjetivación, de clasificación y de jerarquización de los niños en función de un uso más o menos "salvaje" de las categorías servidas por la psicología evolutiva o diferencial, por la psicología social o por cualquiera de los "determinismos" sociológicos o culturales al uso. "Ser culturalmente diferente" se convierte demasiado a menudo, en la escuela, en poseer un conjunto de determinaciones sociales y de rasgos psicológicos (cognitivos o afectivos) que el maestro debe "tener en cuenta" en el "diagnóstico" de las resistencias que encuentra en alguno de sus alumnos y en el diseño de las prácticas orientadas a romper esas resistencias. No otra cosa es lo que la escuela suele entender por "diferencia" cuando se termina el juego de la exhibición, frecuentemente trivializada, de las "particulares" formas que cada uno tiene de vestir, de comer, de cantar y bailar, de contar cuentos o de celebrar las fiestas.

Tampoco sería difícil ironizar sobre el carácter puramente formal que a menudo adquiere en la escuela el mandato de la igualdad, sobre la imposibilidad de un currículum culturalmente diverso como no sea en el reducto intranscendente de las áreas expresivas como la música, el arte, las lecturas literarias o los juegos, y sobre cuántas veces el diálogo no es otra cosa que un medio de regulación de los conflictos, un juego "relacional" para la administración "dulce" de los buenos sentimientos, o un juego lingüístico y argumentativo tan pedagógicamente controlado y evaluado como cualquier otra producción escolar de los niños. En ningún otro lugar como en la escuela el "diálogo democrático" muestra más crudamente su dependencia del poder en tanto que autoritariamente producido y convertido en "instrumento pedagógico".

Quizá la única identidad fuerte que la escuela construya sea la de "alumno" y a lo mejor los únicos vínculos de verdad importantes sean los que se establecen por encima o por debajo o a la contra de la tutela pedagógica del maestro, de su buena conciencia moral y de sus intenciones pedagógicas explícitas.

No sería difícil hacer ver, una vez más, que el mundo se resiste tozudamente a conformarse según nuestras mejores utopías, que todavía hay un abismo entre lo que la escuela pretende y lo que realmente hace y que hay que preguntarse también si la escuela, por su propia lógica de funcionamiento, al menos en nuestro mundo, puede hacer lo que dice que intenta hacer. Pero de todas formas, y por enormes que sean las resistencias de la sociedad a conformarse a nuestras ideas, de las prácticas a conformarse a nuestras teorías, de los niños a conformarse a los proyectos que tenemos para ellos, e incluso de nuestro mundo a que la escuela 
funcione de otra manera, nuestras buenas intenciones pueden permanecer intactas. Quizá nuestra arrogancia esté en la forma y en el tamaño de nuestros proyectos y de nuestras ambiciones, en la forma como nosotros estamos satisfechos de nosotros mismos justamente por mantener esos proyectos y por luchar por ellos a pesar de todas las resistencias que se oponen a su "realización".

Para los profesores de barriada, para aquellos que trabajan en condiciones durísimas intentando que la exclusión no sea la única forma de construcción de la identidad social y cultural de sus alumnos y que la violencia no sea su único modo de relación, las buenas intenciones son un medio de justificar sus prácticas cotidianas y de hacer tolerable su esfuerzo diario. Acaso su única satisfacción (que en este caso es casi una cuestión de supervivencia) esté en mantener la fuerza de sus convicciones y la conciencia de que, a pesar de todo, están trabajando para una causa que vale la pena. En estos casos, la mayoría de las veces, el coraje para el trabajo diario viene de un compromiso ético fundamental para con el dolor concreto y singular que enfrentan cotidianamente y no de la pretensión de realizar utopías más o menos consoladoras convirtiéndolas en objetivos pedagógicos cuidadosamente elaborados y argumentados, políticamente correctos, moralmente decorativos y prácticamente irrelevantes. Por otra parte, y pese a todas las dificultades, la escuela sigue siendo percibida por ellos como una isla en la que todavía sería posible que las relaciones entre sus miembros estuvieran articuladas sobre un cierto diálogo, un cierto respeto, una cierta comprensión. Vista en el contexto de una realidad social circundante durísimamente azotada por el paro, la violencia, la miseria económica y cultural, los exclusivismos y los integrismos de todo tipo, la escuela aún aparece como un lugar donde no todo está perdido, donde continuan latiendo las posibilidades, donde todavía se puede hacer algo.

Pero el discurso sobre lo multicultural que producen muchos de los "intelectuales" del campo pedagógico suele estar impregnado de soberbia moral, de arrogancia intelectual y de oportunismo académico. Las barriadas son simplemente ignoradas o, como mucho, algo "sobre" lo que se habla (y no algo "a partir" de lo que se habla), generalmente sobre la base de estadísticas e informes, y los problemas (y los retos) cotidianos de sus escuelas, de sus alumnos y de sus profesores son tratados bien de una forma tan genérica y abstracta que se hace difícil reconocerlos, o bien de una forma tan convencionalmente patética que se hace difícil no ver ahí un mero efecto retórico de carácter sentimental, con intenciones legitimadoras y desprovisto de toda sinceridad. 
La sospecha es que la construcción pedagógica de la utopía multicultural, junto con el uso emblemático de algunas palabras mágicas, tiene una función ideológica y social que quizá no tenga nada que ver con lo que ocurre en las barriadas y que acaso consista básicamente en la elaboración de nuestras buenas intenciones y en la producción de una imagen amable y satisfecha de nosotros mismos. Por otra parte, a lo mejor esos discursos sirven también para reducir lo inquietante que la presencia del otro extranjero trae consigo, lo que tiene de excesivo e inacomodable, lo que tiene de amenazador para nuestra propia identidad, para nuestras propias representaciones y también, desde luego, para nuestra propia buena conciencia moral.

En un momento en que la retórica de las buenas intenciones multiculturales aparece demasiado a menudo como un efecto publicitario altamente rentable al servicio de la legitimación de intereses políticos y económicos diversos, en un momento en que la representación sabia de la pluralidad cultural es frecuentemente un instrumento para la neutralización por el saber de lo que el otro extranjero tiene de extraño e inabarcable, y en un momento, por último, en que la identidad personal y colectiva se nos muestra como algo ideológicamente fabricado por los aparatos pedagógicos, ideológicos y culturales con vistas a la fijación, la buena administración y el control de las subjetividades, acaso debamos comenzar a sospechar que los extranjeros no son sino el pretexto para la proliferación de esos discursos satisfechos, arrogantes, seguros y asegurados en los que formulamos nuestras intenciones, articulamos nuestros saberes y construimos nuestra identidad.

¿Y si todos esos discursos sobre lo multicultural sirvieran fundamentalmente para asegurar nuestra indiferencia? La indiferencia no tiene nada que ver con la falta de conocimientos o con la pérdida de valores. Más aún, la indiferencia es la cualidad de un ser idéntico, dotado de una identidad firme, cerrada y asegurada. ¿Y si fueran nuestras buenas intenciones, nuestras representaciones sabias y nuestra voluntad de construir el futuro las que constituyeran una identidad segura de sí misma, arrogante y satisfecha, hecha para cancelar la apertura al otro extranjero, la capacidad de escuchar, de responder y de ponerse en cuestión? ¿y si toda esa retórica multicultural no fuera otra cosa que un modo de aliviar nuestra propia inquietud y de disimular la íntima certidumbre de que nosotros también somos extranjeros, que también estamos solos, desarraigados y como arrancados de este nuestro mundo que ya no podemos llamar nuestro? ¿y si la elaboración de nuestras buenas intenciones no fuera sino un modo de ocultar nuestra propia vulnera- 
bilidad o, lo que es lo mismo, una manera de enmascarar la violencia física y simbólica que salvaguarda las frágiles seguridades cotidianas que constituyen nuestra identidad?

\section{II}

La estructura de la comprensión ha sido definida como una mediación entre lo extraño y lo familiar. Gadamer lo formula así: "Hay una polaridad de familiaridad y extrañeza en la que se basa el trabajo hermenéutico (...). La verdadera morada de la comprensión está en esta región intermedia". La comprensión habitaría entonces el lugar fronterizo: el límite donde se daría la tensión entre lo familiar y lo extraño o, lo que es lo mismo, entre lo idéntico y lo diferente, entre lo propio y lo ajeno, entre lo mismo y lo otro. $\mathrm{Y}$ es en ese linde siempre inquieto en el que realizaría su función mediadora.

Esa función intermediaria tendría una doble dimensión: por un lado la comprensión familiarizaría lo extraño; por otro lado, extrañaría lo familiar. Sin la primera dimensión no habría entendimiento puesto que lo extraño, al permanecer como extraño, conservaría siempre una irreductible opacidad que lo haría inasimilable. Pero sin la segunda dimensión el entendimiento no realizaría sus posibilidades críticas y dinámicas, las que conducen a su propia ampliación o transformación, puesto que éstas sólo son activadas por la operación de proyectar lo extraño sobre lo propio.

Lo que ocurre es que estas dos dimensiones de la comprensión suelen ser articuladas de un modo sucesivo y dialéctico de forma que el momento de la negatividad, el extrañamiento, quedaría de alguna forma recuperado en un movimiento final y concluyente de re-familiarización. Se produciría así una serie dialéctica como la siguiente. El intérprete se encontraría primero en una situación de familiaridad consigo mismo y con su mundo, bien aposentado en su identidad, en su propiedad, en su casa. La irrupción del otro como lo extraño constituiría después una cierta turbación de esa identidad satisfecha, de esa propiedad segura y asegurada, de ese hogar en el que sólo habitaba lo familiar y lo acostumbrado. La primera fase de la relación interpretativa, entonces, estaría marcada por la aparición de lo otro extranjero y sería un momento negativo en el que lo familiar sería retado por lo extraño, lo idéntico por lo diferente, lo propio por lo ajeno. En este momento negativo la familiaridad cotidiana quedaría destruída y el intérprete se sentiría como 
arrojado al ámbito de lo extraño, a una suerte de intemperie en la que no hay protección. Desde ahí, desde su identidad momentáneamente turbada y desde su casa temporalmente perdida, el intérprete debería hacer propio lo ajeno y familiar lo extraño, debería domesticar lo que no pertenece al domus, a la casa, debería identificar lo diferente y recuperar la estabilidad perdida, debería por fin re-sedentarizarse (re-territorializarse si usamos la palabra deleuziana) tras un breve y no demasiado peligroso nomadeo (tras una des-territorialización controlada).

En la tradición hermenéutica, por tanto, la comprensión del otro extranjero suele ser considerada como un proceso dialéctico que, comenzando por un momento de extrañamiento, se resolvería finalmente en una recuperada re-familiarización. De ese modo, la inquietud que lo extraño produce quedaría aliviada en tanto que, mediante la comprensión, el otro extranjero habría sido incorporado a lo familiar y a lo acostumbrado. De alguna manera nos habríamos familiarizado a la presencia entre nosotros del otro extranjero en tanto que lo habríamos convertido en algo propio de nuestro mundo, en algo que se plegaría, aunque con una cierta resistencia, a las buenas intenciones que proyectamos sobre su figura, a las representaciones sabias con que imaginamos comprenderlo $\mathrm{y}$ a las formas de identidad en las que reconocemos nuestra hospitalidad.

La comprensión del otro extranjero estaría sometida a una suerte de regulación económica en tanto que derivaría su ley de la oiko-nomía, de la ley del oikos, de la casa, de las normas para la buena administración de la propiedad y para la correcta regulación de los intercambios entre lo que pertenece a la casa y lo que es ajeno a ella. En la comprensión, entonces, lo extraño se contemplaría económicamente, esto es, desde la perspectiva y el interés de lo propio a la casa. La mediación interpretativa entre lo familiar y lo extraño estaría puesta al servicio de la familiaridad y no sería otra cosa que un instrumento de apropiación. El otro, al ser familiarizado y domesticado, se habría convertido en accesible al precio de reducir su extrañeza, al precio, en suma, de ser esquivado como otro y determinado como valor. Algo así es lo que ocurre cuando el discurso sobre lo multicultural rentabiliza la presencia entre nosotros de los extranjeros al proyectar sobre esa presencia enigmática y generalmente muda el despliegue de nuestros saberes, de nuestras prácticas y de nuestras buenas intenciones.

Por otra parte, y desde esa misma perspectiva económica, la diversidad cultural puede ser percibida como riqueza posible: hay que calcular los efectos de lo que viene de afuera en términos de ganancia potencial. Hay que asegurar la ganancia: que lo que viene de afuera venga a incrementar lo que tenemos, pero que nunca nos lo ponga en cuestión; 
que la aportación del otro extranjero amplíe nuestra mente, que nos haga más sabios, que haga más variadas nuestras experiencias, que nos haga más ricos, pero que nunca inquiete lo que somos; que la presencia de los extraños nos haga más dialogantes, más tolerantes, más democráticos, pero que nunca relativice los valores en los que nos reconocemos. La administración y el control de la relación con lo (culturalmente) extraño tiene entonces una función simbólica privilegiada: asegurar y fortalecer nuestra identidad.

Si el otro extranjero es aún, para nosotros, el lugar de aparición de una diferencia irreductible, ¿es posible pensar una forma de comprensión que no esté sujeta a relación económica, que no entre en la lógica de un intercambio orientado a asegurar la ganancia simbólica? ¿es posible un encuentro con el extranjero que salvaguarde la extrañeza como extrañeza y la diferencia como diferencia? ¿es posible que la experiencia del extranjero sea una experiencia de exilio compartido que convierta todo hogar en intemperie y afirme la imposibilidad de toda propiedad y la ausencia de toda morada?

\section{III}

Se ha dicho que la etnografía está ligada a la colonización. Cuando Occidente se hace capaz de dominar el mundo, se cree también capaz de comprenderlo. La comprensión y la apropiación del otro son como las dos caras de una misma ambición, ambas igualmente metódicas y arrogantes. La voluntad de saber y la voluntad de poder se conjugan y ambas expresan la certeza de sí de un mundo lanzado ya a la conquista de la totalidad del mundo. Pero la etnografía está también a veces ligada a la pérdida del mundo, a la sensación de vacío y de inanidad creada en Occidente por la pérdida del mundo. Es ejemplar, a ese respecto, el itinerario de Michel Leiris tal como él mismo lo relata en L'Afrique fantôme y tal como lo comenta en numerosos textos autobiográficos y en esa fascinante serie de autojustificaciones que constituyen los tres prólogos al cuaderno de viaje del cronista de la Misión Dakar-Djibouti: un hombre que parte con la ambición de

romper el círculo de costumbres en el que estaba encerrado, rechazar mi corsé mental de europeo (...), lanzarme en cuerpo y alma a una aventura de la que pudiera decir, en un cierto sentido, que no volvería nunca, puesto que parecía imposible que yo fuera intelectual y moralmente el mismo cuando emergiese de esta inmersión. 
Hay en Leiris un deseo de huída (de sí mismo) y de aventura (en pos de la metamorfosis) una y otra vez exasperado por su inevitable y repetida frustración: "Volvi en 1933 habiendo matado al menos un mito: el del viaje como medio de evasión”. La mayor atadura, aquella que encadena el yo a sí mismo, no puede quebrarse. Pero permanece siempre una extraña inquietud, un permanente desasosiego. En la estela del movimiento surrealista con el que mantuvo estrechas relaciones, Leiris enfatiza el aspecto subversivo de la etnografía, su utilidad para desfondar la certeza de sí de nuestro mundo y su relación con "el intenso deseo que todo hombre debería tener de romper sus límites". Más tarde el compromiso político sustituye al deseo de aventura, pero ahí anida también una voluntad de "ampliación y de olvido de sí mismo" aunque esta vez su medio sea la "comunidad de acción" o la "fraternidad militante". Al final, una misma frustración y una misma melancolía: el viaje africano no transforma al viajero Leiris ni le ofrece tampoco una experiencia de transformación social en la que él pueda entregar y disolver su propia subjetividad. La etnografía se revela incapaz de cumplir sus promesas. Pero la inquietud del antropólogo, nunca calmada, su condición de desarraigado de su propio mundo, de extranjero para sí mismo, le llevó a una forma de comprensión que sus compañeros de viaje no fueron capaces siquiera de adivinar (ocupados como estaban con cumplir los objetivos de su expedición, pensando y actuando como buenos franceses, sin ninguna duda sobre sí mismos, según las instrucciones metodológicas que les habían dado en el Museo del Hombre y según las tareas que su país les había encomendado).

\section{IV}

El otro extranjero aparece, en un primer momento, como pura extrañeza. ¿Quién podría conocerlo realmente? Permanece indescifrable bajo la cubierta de una gentileza quizá excesiva, de una amabilidad a veces exagerada y siempre desarmante. Otras veces se muestra hosco y como replegado sobre sí mismo, construyendo en torno a su piel una barrera que nada atraviesa, lleno de aristas, exhibiendo una voluntad tozuda y encarnizada de aislamiento. ¿Quién podría acercarse a él? Amable o enfurruñado, su presencia remite constantemente a una ausencia sin fondo. Volviendo hacia nosotros su rostro opaco o su rostro falsamente transparente, su proximidad sólo señala hacia una lejanía desmedida.

La extrañeza que el otro extranjero encarna, su radical ausencia y su distancia inconmensurable, no son, sin embargo, neutras, aunque pueden 
ser neutralizadas. Siempre tenemos a nuestra disposición algunos recursos para la neutralización de lo que esa extrañeza puede tener de inquietante. Para neutralizar lo que tiene de inacomodable, el otro extranjero debería ser traído, lo hemos visto ya, a la presencia y a la familiaridad.

La re-presentación (escolar o de cualquier otro tipo) de la diversidad cultural sería justamente la constitución de lo ausente a partir de lo presente y de lo extraño a partir de lo familiar. Dicha representación consiste en presentar al extranjero como ya de antemano conocido y comprendido por medio de su consideración como el re-presentante de una cultura. La representación de la diversidad cultural sería entonces el resultado de una comprensión abarcadora en la que el otro extranjero quedaría subsumido en un contexto cultural que daría cuenta y razón de su extrañeza e identificaría su diferencia.

Por otra parte, y si recordamos la función mediadora de la interpretación, su morada en la región intermedia entre lo extraño y lo familiar, su condición de configuradora y administradora de los límites, comprenderemos enseguida el papel de la re-presentación en la fijación y la estabilización del límite y, a la vez, en la determinación del interior y del exterior, es decir, de lo que pertenece a cada una de las regiones que delimita.

Al mediar entre lo extraño y lo familiar, la interpretación los deslinda y los delimita y, en esa misma operación, los constituye como tales. Del mismo modo que un deslinde de tierras funda la identidad y la propiedad de un territorio (junto con la identidad y la propiedad de los territorios co-lindantes), la interpretación delimita unidades culturales como unidades de sentido y les adjudica una identidad y un valor. Al mismo tiempo, constituye y explicita la diferencia entre lo extraño y lo familiar (entre lo propio y lo ajeno), pero como una diferencia ya capturada y sometida a concepto en tanto que la otredad ya sólo constituye una serie más o menos articulada de identidades diferenciables. Por otra parte, la representación de la diversidad cultural (como una interpretación consolidada y estable) evita que extrañeza y familiaridad se confundan o se inviertan intercambiando sus papeles. Desde este punto de vista, la representación de la diversidad cultural funcionaría, a un nivel simbólico, de modo análogo a la identificación socio-policial del contingente de extranjeros. Establecería una diferencia entre los ciudadanos y los otros y adjudicaría a cada uno una identidad diferente.

Las políticas favorecedoras de la integración realizadas a partir de la socialización monocultural o las políticas mantenedoras de la 
diversidad a través de la configuración de una suerte de pluralismo insularizado tienen una cosa en común: el énfasis en la pureza y la proscripción de toda forma de comunicación y de intercambio. Las políticas multiculturales, por su parte, además de enfatizar el valor positivo de la convivencia, están dirigidas a calcular el valor de la comunicación y de los intercambios en términos de pérdida o ganancia y a regular su flujo reduciendo lo que podrían tener de amenazador y peligroso y fomentando sus potencialidades consideradas "positivas". Desde este punto de vista las políticas multiculturales (tanto si están vehiculadas a través de aparatos pedagógicos como de otro tipo) son análogas a las políticas socio-policiales. Si estas últimas calculan el interés y el valor de la fuerza de trabajo importada o a importar y regulan su flujo, las primeras calculan el interés y el valor de los elementos culturales importados o a importar y regulan su circulación. Las políticas socio-policiales dependen de una economía que calcula un beneficio material o físico a partir de la conversión del extranjero en una mercancía física o en una unidad de explotación abstracta: serían una modalidad de la constitución y la administración de las cosas y de las personas. Las políticas pedagógico-culturales, por su parte, dependen de una economía que calcula un beneficio cultural o simbólico a partir de la conversión del extranjero en un "valor" pedagógico o cultural: constituirían y gestionarían unidades simbólicas.

Un ejemplo de esto es la moda de los "nativos americanos" en los Estados Unidos de América, que ahora está llegando hasta nosotros en forma de libros, pósters, discos, películas y objetos diversos de artesanía. Primero se aniquila una cultura y después se la convierte en mercancía: lo otro como objeto de consumo o el supermercado de la diversidad. El indio Gerónimo, derrotado e inofensivo, terminó trabajando en un circo: lo otro como espectáculo o el circo de la diversidad. En esa lógica, con la diversidad cultural reducida a sus aspectos exteriores y folclóricos (diferencias en la comida, en la ropa, en el lenguaje, en la música, en las fiestas), la educación multicultural puede convertirse en turismo cultural o, aún peor, en una variante escolarizada de una exposición universal o de su versión degradada en parque temático.

Convenientemente re-presentado e identificado, desactivada ya su inquietante extrañeza, el otro extranjero ya no da miedo. La neutralización de su extrañeza no es quizá sino un efecto de nuestra cobardía, de nuestra necesidad de permitirnos sólo encuentros seguros y asegurados, planificados y sin sorpresas, convenientemente pre-vistos y despojados siempre de toda incertidumbre. 
Suprema lección del Bildungsroman: el proceso de formación no comienza por la identificación sino por la des-identificación y la separación, por la salida de casa. La historia de Jacinto, ese Märchen delicioso insertado por Novalis en Los discípulos de Saïs, comienza por un malestar. Hace muchos años, en un país lejano del lado de poniente (es decir, en cualquier tiempo y en un lugar cualquiera), vivía un muchacho extraño, solitario e irritable. Siempre estaba serio y como malhumorado. Sin motivo aparente, estaba marcado por una tristeza y un desconsuelo que parecían infinitos. Jacinto, a diferencia de los otros muchachos, no se siente en casa: no está identificado con su entorno ni consigo mismo. Jacinto es un extraño para los otros y siente en su interior una perpetua inquietud, un permanente desasosiego. Sólo él, el desarraigado, está en disposición de recibir al extranjero, al Wanderer, al viajero errante. El extranjero tiene algo en la mirada y en los gestos que no es de este mundo. Como un mensajero de lo extraordinario, no pide nada ni trae nada para vender. Simplemente se sienta delante de la casa de los padres de nuestro héroe y hace sentir su presencia como encarnación del afuera. Con él llega el impulso definitivo que hace que Jacinto abandone lo estático y lo estable, lo familiar. El extranjero trae la imagen (y la nostalgia) de lo lejano. Y así convierte el malestar inicial (esa inquietud, ese desasosiego) en un impulso centrífugo, en una curva tendida hacia afuera que se abre ya hacia lo desconocido. El joven siente como si tirasen de él: no sabe dónde va, no sabe lo que busca, pero siente que debe marcharse. Extranjero ya para sí mismo y abierto a lo que no se sabe, nada ni nadie podrá retenerle.

\section{VI}

El otro extranjero no se deja representar. No permite que nadie le represente (que nadie hable en su nombre) y no quiere representar a nadie ni a nada. El extranjero no representa nada, sino que es él mismo la pura presencia que burla toda representación, que no admite captura. El otro extranjero aparece aureolado de soledad. No pertenece a nuestro mundo y, al mismo tiempo, está como arrancado del que podría ser su mundo. El otro extranjero aparece como el desarraigado, el que no tiene mundo. Su diferencia es una diferencia de una particular pureza, desnuda, emancipada de cualquier contexto que pudiera dar cuenta de ella. 
Pero su soledad no es sino el espejo de nuestra soledad, de esa soledad que el poder intenta negarnos disfrazándola de esa compañía gregaria e insignificante cuyos lugares (funcionalmente intercambiables) son el supermercado, el espectáculo de masas, el mítin político, el aula, el lugar de trabajo o la televisión. Como el extranjero, tampoco nosotros tenemos un mundo que podamos llamar nuestro. Y también como él sentimos de cuando en cuando que no podemos reconocernos en ninguna de las identidades con las que han pretendido disfrazar esa diferencia sin contenido que se agita en algún sitio de nuestro cuerpo y que no tiene más realidad que la de una pura inquietud, un irreductible desasosiego. ¿No será el extranjero el que nos trae la imagen inquietante de nuestra propia soledad y de nuestro propio desarraigo? ¿No será el extranjero el que nos hace conscientes de que también nosotros somos la morada de lo ausente? ¿No será el extranjero el que mantiene en nosotros despierto el dolor y el que provoca en nosotros ese deseo que permanece deseo, esa tensión sin objetivo? ¿No será el extranjero el que nos hace extranjeros y, justamente por eso, el que nos permite ser nosotros mismos?

Recebido e aprovado em junho de 2002. 